EDITORIAL

\title{
Students as Partners in Crisis? Student Co-Editors' Perspectives on COVID-19, Values, and the Shift to Virtual Spaces
}

\author{
*Anita Ntem, Charter Management Office, Democracy Prep Public Schools, USA \\ Elaina Nguyen, Arts \& Science Program and MacPherson Institute, McMaster University, \\ Canada
}

Caelan Rafferty, Faculty of Business, Economics, and Law, The University of Queensland, Australia

Connie Kwan, Faculty of Education, The University of Hong Kong, Hong Kong

\begin{abstract}
Abderrahim Benlahcene, School of Education and Modern Languages, Universiti Utara Malaysia, Malaysia
\end{abstract}

Contact: ani.ntem@gmail.com

Engaging in partnership practices can be an activity fraught with uncertainty for all participants at the best of times. However, this uncertainty has been heightened by the onset of the COVID-19 pandemic. Indeed, COVID-19 has challenged this generation to endure circumstances where face-to-face communication is often no longer considered safe or appropriate. In response, universities around the world have shifted to virtual curricula and events. For some students and staff, this online and off-campus mode of connecting may be completely new and uncharted territory. Under this veil of uncertainty, is it possible to pursue and sustain partnership practices using virtual platforms?

As student co-editors for the International Journal for Students as Partners (IJSaP) hailing from five countries (Australia, Canada, Hong Kong, Malaysia, and the United States), we recognize how the pandemic has impacted each of us in distinct ways, thereby encouraging us to wrestle with the reality of our new "normal." More specifically, while we continue to understand partnership to be "a collaborative, reciprocal process through which all participants have the opportunity to contribute equally, although not necessarily in the same ways, to curricular or pedagogical conceptualization, decision-making, implementation, investigation, or analysis" (Cook-Sather, Bovill, \& Felten, 2014, pp. 6-7), we have been reflecting on what this new normal means for our partnership praxis.

In this editorial, we argue that the pursuit, application, and renegotiation of values central to partnership praxis (e.g., authenticity, honesty, responsibility, inclusivity, reciprocity, empowerment, trust, respect, courage, plurality [Healey, Flint, \& Harrington, 2016; Cook-Sather 
et al., 2014]) will enable partnership to be realized in virtual environments. We acknowledge that the list of values outlined above is not exhaustive and some have been thoughtfully critiqued as more complex or even at odds with personal practices (see de Bie, 2020; Bovill, 2017). Nevertheless, in referring to these values, we hope to think through how our understanding of partnership can evolve with reflections on this crisis. In what follows, we first distinguish between those new to partnership and those who have engaged in partnership in the past. Specifically, for those new to partnership, the process of engagement may centre on figuring out how to realize partnership values in a virtual context. In contrast, for those who have already engaged in face-to-face, virtual, or hybrid partnership arrangements in the past, this period of uncertainty may mean reassessing how partnership values can apply to their current practice. Finally, we then reflect from our own perspectives on lessons learned from the virtual partnerships that have taken place over the past few months and the implications for future partnership practice.

In addition to our own experiences, this editorial draws on data from two separate, informal studies: one focused on student partners and another mainly on staff perspectives. The first study was conducted in the third week of April 2020 by Alison Cook-Sather, Director of the Teaching and Learning Institute at Bryn Mawr and Haverford Colleges, who hosted, in collaboration with Nandeeta Bala, a student partner at Vassar College, virtual meetings of 25 student partners who worked with instructors at nine colleges and universities in the United States through the sudden shift to online instruction (Cook-Sather \& Litvitskiy, 2020). The second is a community poll on learner-teacher partnerships in the time of COVID-19, with $89.6 \%$ of participants describing themselves as staff (Matthews, Cook-Sather, Godbold, Healey, \& Rafferty, 2020).

Amidst this uncertainty, we believe that virtual partnership practices are a viable and important avenue to facilitate collaborative and equitable engagement between students and staff.

\section{REALIZING VALUES IN STARTING PARTNERSHIPS}

New partnerships typically focus on establishing dialogue, developing meaningful relationships, and negotiating trust between students and staff. These processes help partners feel more comfortable collaborating by breaking down traditional, student-staff power hierarchies (Matthews, 2017; Dwyer, 2018). Given the circumstances, an understandable concern is whether a shift to virtual spaces may hinder or discourage these foundational steps. Moreover, a lack of access to technology or reliable bandwidth may limit accessibility for the time being. As McCreadie (this issue) points out in her review of Matthews et al.'s (2020) community poll, the prevalent assumption that students are more familiar with technology "explicitly disguises and underplays the important socioeconomic advantages necessary for students to meet this expectation" (McCreadie, 2020, p.156). Thus, primacy should be placed on shared dialogue about shifting roles, responsibilities, and circumstances to allow us to be attentive to access inequalities and the accompanying assumptions.

However, virtual spaces may also alleviate some of the initial awkwardness of meeting in person by providing different opportunities for relationship building without the additional

Ntem, A., Nguyen, E., Rafferty, C., Kwan, C. \& Benlahcene, A. (2020). Students as partners in crisis? Student co-editors' perspectives on COVID-19, values, and the shift to virtual spaces, International Journal for Students as Partners, 4(2). https://doi.org/10.15173/ijsap.v4i2.4432 
strain that may come with in-person interactions (Impastato \& Topper, 2020). As such, virtual alternatives are entirely acceptable, and may even be preferable, for starting dialogue in partnerships by expediting connection-making between individuals and communities. The issue of access, though, remains a challenge.

Partnership participants also commonly identify quick, informal conversations as being the most generative in building relationships (Jensen \& Bennett, 2016; Flint \& Millard, 2018). In starting partnerships online, one student partner from Cook-Sather \& Livitskiy's (2020) informal study identified the need to "check in with each other often, not just about class but about how each other is doing and what can be done to best support each other". Thus, realizing trust virtually may involve explicitly making space and time for partners to courageously engage in these informal conversations across multiple platforms.

It is also important to be wary of how the uptake of virtual-only formats may lead to new, superficial forms of partnership that claim to incorporate student voices without devoting serious effort to exploring notions of power, agency, and expertise. While this issue is not unique to virtual environments, superficial approaches to student engagement may be more prevalent in the current global environment shaped by fiscal conservatism and varying technological access.

Moreover, in contexts where partnership is still new and emerging, reservations and/or resistance can be exacerbated in periods of hyper-uncertainty. Describing their opinion on the role of pedagogical partnerships during the rapid shift to online learning, one staff participant from the Matthews et al. (2020) online poll noted, "I'm not [sure] that the idea is well enough formed in the first place. Too many observations of colleagues I [sic] sung this approach to abdicate responsibility for curriculum guidance". Other respondents pointed out that time pressure, emphasis on low-cost, and technology barriers meant that partnerships were not feasible to start in their contexts (Matthews et al., 2020). In these situations, practicing honesty might counterintuitively mean accepting certain labour- and time-intensive partnerships as not currently feasible for pragmatic reasons.

Yet, in beginning the partnership journey, we have found it helpful to think about the values and ethos of partnership, not as something contained within and limited by formal partnership practices, but as something practiced in everyday life.

\section{REASSESSING VALUES IN ESTABLISHED PARTNERSHIPS}

For student and staff partners with partnership experience, it may be necessary to revisit partnership values to adapt to ongoing changes. For some, previous familiarity with the notions of power, agency, and expertise may provide the necessary foundations regardless of the medium in which partnership is conducted. Weiler and Williamson (2020) offer such an account, in which they emphasize how their strong foundation of trust, established prior to the shift online, allowed them to "re-engage our existing partnership to facilitate a transition during times of crisis" (p. 2). Other partners who have had past experiences engaging in virtual partnerships or blended forms of partnership (i.e., combined virtual and face-to-face engagement) may find it an easier transition. As one poll respondent put it, "my engagement

Ntem, A., Nguyen, E., Rafferty, C., Kwan, C. \& Benlahcene, A. (2020). Students as partners in crisis? Student co-editors' perspectives on COVID-19, values, and the shift to virtual spaces, International Journal for Students as Partners, 4(2). https://doi.org/10.15173/ijsap.v4i2.4432 
has always been at a distance. Adjustment has therefore not been necessary" (Matthews et al., 2020).

However, even for partners with virtual experience, it may be difficult to operate as usual at this time. As one participant noted:

Not everyone is experiencing a rapid transition to online teaching and learning, as some of us have been doing it for many years, and what is happening now is akin to business as usual in a teaching/learning sense except insofar as some individuals are having a tough time for reasons outside of study (financial, stress/anxiety, family pressures, etc.). While these challenges have always existed, they are exacerbated for some at this time.

(Matthews et al., 2020)

Fulfilling the work of partnership-guiding the process, setting the time frame, and establishing an outline for discussion - needs to occur alongside a rebalancing of work, study, and personal responsibilities.

Similar to starting partnerships, re-visiting partnership values may mean having honest conversations and regular check-ins about your capacity for engagement, expressing your needs, and respecting what all partners need moving forward. As one poll respondent wrote, "my sense is what tenuous partnerships there were have been strained if not dropped. The sheer amount of time it takes to put a course fully online, find those who have 'slipped under' and find a way to get them working effectively, has put so much off the agenda" (Matthews et al., 2020). Perhaps in some cases, a pause in partnership is necessary to deal with all the overwhelming vicissitudes of life. Conversely, partnership can be conceptualized and positioned to support such transitions, as has been the case through the Summer Pedagogical Partnership program developed at Bryn Mawr and Haverford Colleges (Raber, 2020). Additionally, a new program is being developed at Syracuse University to address the intersecting needs of campus climate and teaching and learning in the COVID-19 context, as well as student placement given that typical field placements are unavailable.

Despite the challenges of the pandemic, virtual partnerships can be an effective way of developing empowering relations between students and staff. As one partner stated, "I actually think that in some cases the current transition developed or strengthened pedagogical partnerships" (Matthews et al., 2020). Thus, effective student engagement remains crucial. Whether or not students and staff explicitly take up partnership work, the values of mutual respect, reciprocity, and shared responsibility can ground our work in higher educationwhether online or face-to-face.

\section{LESSONS AND IMPLICATIONS FOR PARTNERSHIP WORK IN THE FUTURE}

As the number of COVID-19 cases fluctuates worldwide, distancing guidelines and safety precautions remain in flux. Even though some countries have begun to relax physical distancing measures, it is undeniable that the social, emotional, economic, and psychological impacts of the pandemic are likely to be felt for a long time. Indeed, as some in the partnership 
community begin transitioning back towards face-to-face or blended media, participants may undertake a prolonged period of reflection on partnership work.

Specifically, given the ubiquity of virtual partnerships to meet physical distancing requirements, there may be greater consideration of hybrid or virtual models of partnership in the future. While virtual partnerships have existed for a while, and certainly we, as student editors for an international partnership journal, have worked together virtually pre-pandemic, there is limited partnership work that explicitly reflects on the experiences of participating in virtual partnerships (for some exceptions, see Moorehouse \& Oh, 2019; Jardine, 2020). The successful and generative virtual partnerships that have recently emerged have led to more recent attention to the specifics of virtual experiences. As a result, future practice may include more virtual and blended approaches.

Already, this increased attention to virtual partnership and the values that inform it has taught us two lessons for partnership generally.

First, we note an increased awareness of the similar, yet distinct, ways students and staff are vulnerable. While staff have always had vulnerabilities, this has been under-discussed in the context of partnership, and from our perspective as students, this vulnerability has never been so clear. The rapidity of the change to new and unfamiliar spaces has unfortunately left staff with the need to urgently seek feedback on their approaches, a process that can be emotionally and physically draining. Seeing this added pressure has reinforced our responsibilities as students to be mindful of the pressures staff face, particularly those in less privileged positions. Concurrently, this also encourages us, as student partners, to be mindful of how we enact and uphold shared responsibilities in any partnership space.

Secondly, while collaborating virtually on this editorial was necessary because of distance rather than the pandemic per se, the absence of non-verbal cues has made us notice how we must be more intentional in our actions and words. We find ourselves more compassionate, empathetic, and purposeful in asking questions to both check in about each other's opinions and clarify any misunderstandings. As things return to "normal," remaining observant and intentional will continue to be important for all partners.

While the crisis has shaken many of us, we have certainly found this process to be generative and useful for enabling us to continue to engage in practices that are integral to our humanity.

\section{CONCLUSION}

The shift in partnership medium from predominantly face-to-face to virtual environments has led to the exploration and reconceptualization of existing partnership values in virtual space. For new partnerships, while it may seem harder to realize the values of partnerships in physically different locations, virtual media offer new opportunities to build partnership relationships in different ways that can be just as meaningful as those in physical spaces. For existing partnerships, the reconceptualization of existing values can drive a renegotiation of partnership processes as they apply in virtual contexts. The shift to virtual spaces will likely give rise to a general uptake of hybrid partnership models in the future, especially as we transition back to in-person learning. Virtual partnership practices have highlighted the

Ntem, A., Nguyen, E., Rafferty, C., Kwan, C. \& Benlahcene, A. (2020). Students as partners in crisis? Student co-editors' perspectives on COVID-19, values, and the shift to virtual spaces, International Journal for Students as Partners, 4(2). https://doi.org/10.15173/ijsap.v4i2.4432 
ever-present vulnerability of both students and staff. Finally, they have demonstrated the need to remain intentional and mindful during partnership and the applicability of partnership values to new and unfamiliar practices. Therefore, perhaps instead of returning to "normal," we can draw on the lessons we have learned from the shift to virtual spaces and create a new normal (see Matias, 2020).

In sum, it is essential to remain open-minded and cognizant of the values that build and vitalize partnership practice such as respect, reciprocity, and shared responsibility (Cook-Sather et al., 2014), and authenticity, honesty, responsibility, inclusivity, reciprocity, empowerment, trust, courage, and plurality (Healey et al., 2014). These are a few of the many important values that partners need to establish and continuously reflect on to ensure the longevity and productiveness of partnerships, regardless of their mode of engagement.

Ultimately, we need to remember and implement the values that encourage and fortify the meaning of partnership and that anchor and sustain our partnership praxis, especially in times of crisis.

\section{ACKNOWLEDGEMENTS}

Thank you to the IJSaP editorial team for their guidance and support throughout the development process of this editorial. Also to Kelly Mathews for the survey "Learner-Teacher Partnership in Times of COVID-19: A Community Poll to Share Practices and Perspectives" and Alison Cook-Sather and Nicole Litvitskiy's "Student partners' Recommendations Regarding Remote Teaching and Learning" and the people who volunteered their time and insights in their responses to those surveys.

\section{NOTES ON CONTRIBUTORS}

Anita Ntem is a recent graduate of Bryn Mawr College, where she was a student partner and researcher in the SaLT program through the Teaching and Learning Institute. She is currently the special advisor to the CEO at Democracy Prep Public Schools, United States.

Elaina Nguyen is a recent graduate of the Arts \& Science Program at McMaster University, where she was a student partner at the Paul R. MacPherson Institute for Leadership, Innovation, and Excellence in Teaching.

Caelan Rafferty is a sixth year Bachelor of Economics/Law (Honours) student from the University of Queensland, where he is a student partner.

Connie Kwan is a recent graduate of the University of Hong Kong, where she is a student partner and researcher.

Abderrahim Benlahcene is a recent PhD graduate of educational psychology at Universiti Utara Malaysia, where he is a student partner. 


\section{REFERENCES}

Bovill, C. (2017). A framework to explore roles within student-staff partnerships in higher education: Which students are partners, when, and in what ways?. International Journal for Students as Partners, 1(1). https://doi.org/10.15173/ijsap.v1i1.3062

Cook-Sather, A., Bovill, C., \& Felten, P. (2014). Engaging students as partners in learning and teaching: A guide for faculty. San Francisco: Jossey-Bass.

Cook-Sather, A., \& Litvitskiy, N. (2020). Student partners' recommendations regarding remote teaching and learning [Online resource]. Retrieved from https://docs.google.com/document/d/1rNnVPJNukBuW3SDUQHzWBJ7u7GJmmlJBZBcWa65jGs/edit

de Bie, A. (2020). Respectfully distrusting 'students as partners' practice in higher education: Applying a Mad politics of partnership. Teaching in Higher Education, 1-21. https://doi.org/10.1080/13562517.2020.1736023

Dwyer, A. (2018) Toward the formation of genuine partnership spaces. International Journal for Students as Partners, 2(1), 11-15. https://doi.org/10.15173/ijsap.v2i1.3503

Flint, A., \& Millard, L. (2018). "Interactions with purpose": Exploring staff understandings of student engagement in a university with an ethos of staff-student partnership. International Journal for Students as Partners, 2(2), 21-38. https://doi.org/10.15173/ijsap.v2i2.3410

Healey, M., Flint, A., \& Harrington, K. (2016). Students as partners: Reflections on a conceptual model. Teaching \& Learning Inquiry, 4(2), 8-20. https://doi.org/10.20343/teachlearninqu.4.2.3

Impastato, J., \& Topper, L. (2020). Support systems and transgressive hierarchies: Insights we gained through the transition online while planning for pedagogical partnership. Teaching and Learning Together in Higher Education, 30. Retrieved from https://repository.brynmawr.edu/tlthe/vol1/iss30/2

Jardine, H. E. (2020). Positioning undergraduate teaching and learning assistants as instructional partners. International Journal for Students as Partners, 4(1), 48-65. https://doi.org/10.15173/ijsap.v4i1.4032

Jensen, K., \& Bennett, L. (2016). Enhancing teaching and learning through dialogue: A student and staff partnership model. International Journal for Academic Development, 21(1), 4153. https://doi.org/10.1080/1360144X.2015.1113537

Matthews, K. E., Cook-Sather, A., Godbold, N., Healey, M., \& Rafferty, C. (2020). Learnerteacher partnerships in times of COVID-19: A community poll to share practices and perspectives [Online poll]. Brisbane: The University of Queensland. Retrieved from https://www.surveymonkey.com/stories/SM-RTB68869/

Matthews, K. E. (2017). Five propositions for genuine students as partners practice. International Journal for Students as Partners, 1(2), 1-9. https://doi.org/10.15173/ijsap.v1i2.3315 
McCreadie, C. (2020). Learner-teacher partnership in times of COVID-19: Community poll review. International Journal for Students as Partners, 4(2), 155-157. https://doi.org/10.15173/ijsap.v4i2.4371

Matias, P. (2020). Four sides of transition. Teaching and Learning Together in Higher Education, 30. Retrieved from https://repository.brynmawr.edu/tlthe/vol1/iss30/7

Moorhouse, B. L., \& Oh, M. H. M. (2019). Students as partners beyond formal education: A mentoring partnership in the first year of teaching. International Journal for Students as Partners, 3(2), 156-162. https://doi.org/10.15173/ijsap.v3i2.3893

Raber, R. (2020). Students Help Professors Prepare More Equitable Classrooms. https://www.haverford.edu/college-communications/news/students-help-professorsdevelop-more-equitable-classrooms

Weiler, K., \& Williamson, A. (2020). Partnering to build responsive learning communities that support students in crisis. Teaching and Learning Together in Higher Education, 30. Retrieved from https://repository.brynmawr.edu/tlthe/vol1/iss30/3 